\title{
Electromyography of extraocular muscles in Duane's syndrome
}

\author{
I. M. STRAGHAN AND B. H. BROWN \\ Hallamshire Hospital, Sheffield
}

The electromyographic (EMG) study of patients with Duane's retraction syndrome has shown that there is a gross abnormality of innervational pattern in this condition. Most commonly the lateral rectus is affected and shows an innervation differing from the normal in several respects.

The first description of the EMG pattern in two patients came from Breinin (1957) when he reported little activity from one lateral rectus, which was found to be fibrotic and cordlike at operation. His other patient showed a low amplitude firing pattern with recruitment in adduction only. Papst and Esslen (1960), investigating five clinically typical cases, found increased innervation in the lateral rectus only in adduction. In five cases with minimal lid narrowing, co-contraction of the lateral and inferior rectus muscles was recorded in four cases and of the lateral and superior rectus muscles in one. Fourteen cases examined by Sato (1960) showed abnormal EMG responses from the lateral rectus muscles; six gave a paradoxical response (i.e. innervation decreasing in abduction and increasing in adduction), four gave an unvarying response with different gaze positions, and two showed a response which increased and decreased in the correct sense with abduction and adduction but to a lesser extent than normal. From the other two cases no response was obtained. Four cases reported by Orlowski and Wojtowicz (Ig62) showed that the lateral rectus muscles were innervated in the correct sense in horizontal gaze but with incomplete inhibition on adduction and poor recruitment in abduction compared with the normal response. These authors also found increased firing on downgaze from the lateral rectus in three cases and on upgaze in two cases, and postulated co-innervation between the superior, inferior, and lateral rectus muscles. Papst (1962) categorized different clinical varieties of Duane's syndrome and correlated them with abnormal cocontraction of:

(I) Medial and lateral rectus;

(2) Superior and lateral rectus;

(3) Inferior and lateral rectus;

(4) Lateral rectus and several other muscles.

Burger (1963) found paradoxical innervation of the lateral rectus with low amplitude traces in two cases. This pattern remained unaltered when the medial rectus was rendered akinetic by local anaesthesia. Two further cases investigated by Orlowski and Krych (1963) showed paretic lateral rectus muscles with co-contraction between this and the inferior rectus (and to a lesser extent the superior rectus). Blodi, van Allen, and Yarbrough ( 1964 ), in two of six cases of Duane's syndrome, found abnormal firing of the 
medial rectus; one showed no change in the firing pattern with different gaze positions and the other showed paradoxical innervation. In two cases the lateral rectus showed an unvarying response with eye movement and in two the lateral rectus showed paradoxical innervation.

A further eight cases were reported by Huber, Esslen, Kloti, and Martenet (1964). In one of six clinically typical cases, the lateral rectus showed a constant response in all gaze positions, and five showed a diminished and paradoxical firing pattern. Two cases showing defective adduction as the major feature demonstrated increasing discharge from the lateral rectus in abduction and adduction compared with the primary position. A patient with marked upshoot on adduction was found to have no electrical response from the lateral rectus and an absent response from the inferior rectus in adduction unless the unaffected eye was occluded when the latter finding was not present (Achtiani and Wollensak, 1966). Dell'Aquila and Molinari (1966), investigating seven cases, reported three with electrically silent lateral rectus muscles, two with a diminished but unvarying response, and two in which the lateral rectus response was of paradoxical type. Ten cases reported by Zauberman, Magora, and Chaco (1967) showed four types of pathological EMG response from the lateral rectus muscles:

(r) The innervation was of normal pattern but increased on adduction;

(2) The trace was of neuropathic pattern and increased on adduction;

(3) The trace was of neuropathic pattern and increased on abduction;

(4) There was no electrical activity.

They used a method of frequency analysis and the neuropathic pattern probably refers to longer than normal spike duration. Ambrosio and d'Esposito (1957) attempted to examine four of six cases electromyographically but their findings of silent medial and lateral rectus muscles, which do not correspond to the clinical findings, probably reflect incorrect needle position.

Huber and Esslen (1969) stated that, whether abduction, adduction, or both were defective, a paradoxical lateral rectus innervation was present. Zauberman and Magora ( 1969 ) added another bilateral case with paradoxically innervated lateral rectus muscles. with a normal amplitude trace and normal spike duration on EMG.

\section{Subjects}

All the patients reported here were typical cases of Duane's syndrome with definite limitation of abduction, and retraction of the globe and lid narrowing on adduction. Some showed upshoot or downshoot on extreme attempted adduction, but this feature was not investigated by electromyography and is not reported.

\section{Method}

Patients were examined in the recumbent position after surface anaesthesia of the eye with Amethocaine $0 \cdot 5$ per cent. Fine concentric needle electrodes (Rank Medical Electrical) were used and the record was amplified and displayed on a storage oscilloscope (Tektronix 564 with $2 \mathrm{~A} 6$ I amplifier) and recorded on magnetic tape (Phillips recorder EL3302). An audio output was used to help obtain accurate placement of the electrode in the muscles. The recorded signals were subjected to analysis by two automated methods (Brown, Whitaker, and Moosa, 1971; Moosa and Brown, 1972). Usually only the medial and lateral rectus muscles were sampled. 


\section{Results}

The results of the EMG investigation are given in Table I. The fourth column shows the obvious gross anomalies of the EMG record.

Table I Results of EMG examination in twenty eyes with Duane's syndrome. The fourth column shows gross visible anomalies of the EMG record compared with the normal pattern

\begin{tabular}{|c|c|c|c|}
\hline Case no. & Sex & Eye & Abnormal EMG findings \\
\hline I & $\mathbf{F}$ & $\mathbf{L}$ & $\begin{array}{l}\text { Lateral rectus showed no change with gaze position } \\
\text { Diminished amplitude }\end{array}$ \\
\hline 2 & $\mathbf{F}$ & $\mathrm{L}$ & $\begin{array}{l}\text { Lateral trectus showed slight paradoxical innervation } \\
\text { Normal amplitude }\end{array}$ \\
\hline 3 & $\mathbf{F}$ & $\mathbf{L}$ & $\begin{array}{l}\text { Lateral rectus showed paradoxical innervation } \\
\text { Normal amplitude }\end{array}$ \\
\hline 4 & $\mathbf{M}$ & $\mathbf{L}$ & $\begin{array}{l}\text { Medial rectus showed paradoxical innervation } \\
\text { Slightly subnormal amplitude }\end{array}$ \\
\hline 5 & $\mathbf{M}$ & $\mathrm{L}$ & $\begin{array}{l}\text { Lateral rectus showed paradoxical innervation } \\
\text { Diminished amplitude }\end{array}$ \\
\hline 6 & $\mathbf{M}$ & $\mathbf{L}$ & $\begin{array}{l}\text { Lateral rectus showed no change with gaze position } \\
\text { Small amplitude }\end{array}$ \\
\hline 7 & $\mathbf{F}$ & $\mathbf{R}$ & $\begin{array}{l}\text { Lateral rectus showed no change with gaze position } \\
\text { Small amplitude }\end{array}$ \\
\hline 8 & $\mathbf{M}$ & $\mathbf{L}$ & $\begin{array}{l}\text { Lateral rectus showed paradoxical pattern } \\
\text { Small amplitude }\end{array}$ \\
\hline 9 & $\mathbf{F}$ & $\mathbf{R}$ & $\begin{array}{l}\text { Lateral rectus showed no change with gaze position } \\
\text { Normal amplitude }\end{array}$ \\
\hline 10 & $\mathbf{M}$ & L & $\begin{array}{l}\text { Lateral rectus showed trace increasing and decreasing } \\
\text { in correct sense but less than normal }\end{array}$ \\
\hline I I & $\mathbf{F}$ & $\mathbf{R}$ & $\begin{array}{l}\text { Lateral rectus showed no change with gaze position } \\
\text { Small amplitude }\end{array}$ \\
\hline 12 & $\mathbf{F}$ & $\mathbf{R}$ & $\begin{array}{l}\text { Lateral rectus responded in correct sense but } \\
\text { incompletely. Diminished amplitude }\end{array}$ \\
\hline 13 & $\mathbf{F}$ & L & $\begin{array}{l}\text { Lateral rectus showed no change with gaze position } \\
\text { Normal amplitude }\end{array}$ \\
\hline 14 & $\mathbf{F}$ & $\mathbf{L}$ & $\begin{array}{l}\text { Lateral rectus showed paradoxical pattern } \\
\text { Diminished amplitude }\end{array}$ \\
\hline I 5 & $\mathbf{F}$ & $\mathrm{L}$ & $\begin{array}{l}\text { Lateral rectus showed paradoxical pattern } \\
\text { Normal amplitude }\end{array}$ \\
\hline I 6 & $\mathbf{M}$ & $\mathrm{R}$ & $\begin{array}{l}\text { Lateral rectus showed no change with gaze position } \\
\text { Normal amplitude }\end{array}$ \\
\hline 17 & $\mathbf{F}$ & $\mathbf{L}$ & $\begin{array}{l}\text { Lateral rectus showed no change with gaze position } \\
\text { Normal amplitude }\end{array}$ \\
\hline I 8 & $\mathbf{M}$ & $\mathbf{L}$ & $\begin{array}{l}\text { Lateral rectus showed paradoxical pattern } \\
\text { Normal amplitude }\end{array}$ \\
\hline 19 & $\mathbf{F}$ & $\mathbf{L}$ & $\begin{array}{l}\text { Lateral rectus showed no change with gaze position } \\
\text { Diminished amplitude }\end{array}$ \\
\hline $20^{*}$ & $\mathbf{F}$ & $\mathbf{R}$ & $\begin{array}{l}\text { Lateral rectus showed no change with gaze position } \\
\text { Diminished amplitude }\end{array}$ \\
\hline
\end{tabular}

*This was the fellow eye of 19

The results of the signal analysis of the EMG tracings of the medial and lateral rectus muscles of Cases 6, 7, 8, 9, I I, I 2, I 3, and I 5 are given in Table II (opposite).

Two methods were used for signal analysis:

(A) Giving the average weighted mean frequency (Brown and others, I97 I Moosa and Brown, 1972) using a special-purpose analogue computer. 
(B) Similar to that described by Rose and Willison (1967), using a special-purpose digital computer (Biomac roro) giving a figure for the average spike duration (ignoring small amplitude signals).

Table II Summary of results of two methods of signal analysis (土 one standard error). Both methods show a significant difference in the results for the lateral rectus muscles between cases of Duane's syndrome and normal subjects.

(Method A $P<0.03 ;$ Method B $P<0.03$ ).

\begin{tabular}{|c|c|c|c|}
\hline Analysis & Control & Duane's syndrome & Muscle \\
\hline \multirow[t]{2}{*}{$\overline{\text { Method } A}$} & $630 \pm \underset{(n=8)}{53 \mu \text { sec. }}$ & $\begin{array}{c}935 \pm \begin{array}{l}114 \mu \text { sec. } \\
(\mathrm{n}=8)\end{array}\end{array}$ & Lateral rectus \\
\hline & $\begin{array}{c}535 \pm \underset{(n=\mu ~ s e c}{ } \\
(n=8)\end{array}$ & $\begin{array}{c}545 \pm 98 \mu \text { sec. } \\
(n=9)\end{array}$ & Medial rectus \\
\hline \multirow[t]{2}{*}{ Method $B$} & $544 \pm \underset{(\mathrm{n}=8)}{46 \mathrm{~Hz}}$ & $423 \pm \underset{(n=8)}{35} \mathrm{~Hz}$ & Lateral rectus \\
\hline & $6_{41} \pm \underset{(n=8)}{67}$ & $63^{8} \pm \underset{(n=8)}{59 \mathrm{~Hz}}$ & Medial rectus \\
\hline
\end{tabular}

The Figure illustrates one case analysed by the second method of signal analysis comparing the results from one normal person with those from a case of Duane's syndrome. The peak of the duration graph is shifted to the right in the lateral rectus of the patient. (The mode of the graph in this method was used for the figures in Table I). Both methods

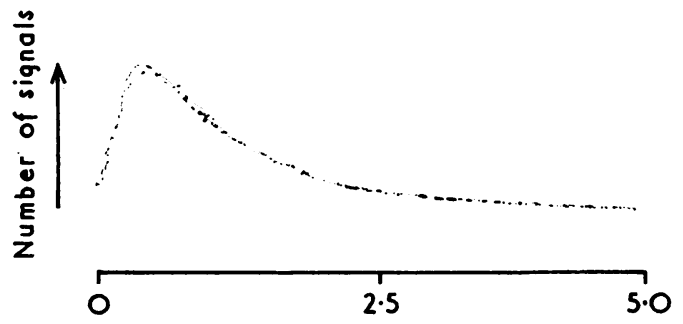

Duration (msec.)

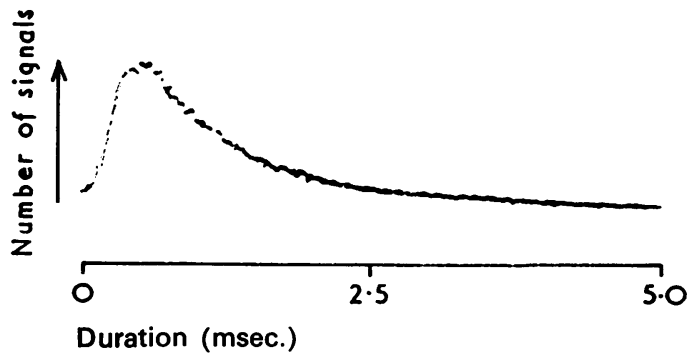

(a) Normal

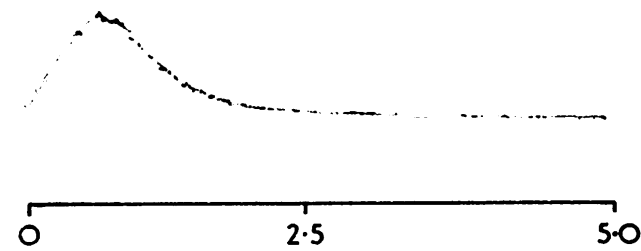

(b) Duane's syndrome

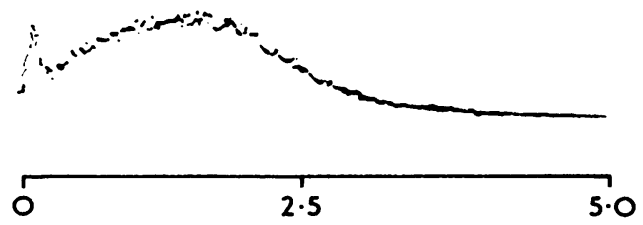

FIGURE

(a) Results of first method of EMG signal analysis in a normal subject.

(b) Results of the same analysis in a subject with Duane's syndrome.

Medial rectus left column, lateral rectus right column. The lateral rectus in (b) has longer spike durations than normal. 
give results showing increased spike duration (i.e. decreased frequency) in the lateral rectus muscles in patients with Duane's syndrome.

\section{Discussion}

From the results presented here and from the previous literature it would appear that the most common EMG abnormality found in Duane's syndrome occurs in the lateral rectus of the affected eye. This may show a spectrum of abnormal activity from a paradoxical innervation (maximal in adduction and minimal in abduction) through an unvarying response independent of gaze position to a response which increases in abduction and decreases in adduction but does so to a lesser extent than normal.

Only one other series (Zauberman and others, 1967) gives results of signal analysis, and these authors also report increased spike duration from the lateral rectus muscles in Duane's syndrome. This cannot easily be accounted for by the current explanations that the syndrome is due to an abnormal distribution of the third nerve (Hoyt and Nachtigaller, i 965) or to a brain stem anomaly (Blodi and others, i 964).

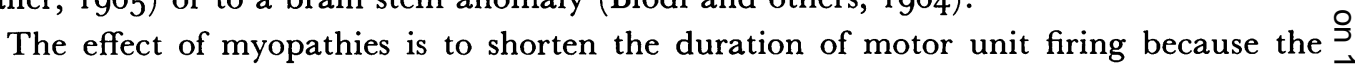
units are reduced in size, and in any event Duane's syndrome is not thought to be pro- $\rightarrow$ gressive. Denervation and subsequent re-innervation could give rise to larger than normal motor units and longer spike durations. Three patients with the third nerve misdirection $\stackrel{\infty}{+}$ syndrome were investigated with this in view, and the muscles clinically involved were $\vec{\theta}$ studied. Analysis of the EMG signals by the same methods gave frequencies and durations $N$ within the normal range.

A relative increase in the slow fibres in the extraocular muscles might give rise to a lower than normal average frequency, as there is some evidence that these fibres can be recorded electromyographically (Ozawa, Cheng-Minoda, Davidowitz, and Breinin, 1969) and that the average duration of a spike from these fibres appears to be of the order of $4 \mathrm{msec}$. A further possibility is that the distribution of motor fibres in each motor unit is different from normal. If the action potentials are not synchronous then the resultant compound potential will be of longer duration. Should the constituent fibres be physically further separated than normal with consequent more variable terminal nerve delays in patients with Duane's syndrome, then the result could be the increase in duration found experimentally. This might occur if fibrosis of the lateral rectus was a fact as earlier authors thought (Wolff, I90I). The gross abnormalities in the electromyographic record, e.g. 오 paradoxical innervation, still await an explanation on the basis of primary muscle pathology.

\section{Summary}

The horizontal rectus muscles of twenty eyes with Duane's syndrome were examined by EMG. The lateral rectus in nineteen instances showed gross anomalies of firing pattern, varying from paradoxical innervation to innervation in the correct sense but with incomplete inhibition in adduction and recruitment in abduction. The amplitude of the signal from the lateral rectus was often reduced. Signal analysis of the EMG in eight cases showed the lateral rectus to have longer than normal spike durations.

This work was supported by a research grant from the United Sheffield Hospitals. We should like to thank Miss J. Mein for assistance with the clinical side of these investigations.

I.M.S. also wishes to acknowledge the co-operation of his Consultant colleagues, Mr. A. Stanworth, Mr C. A. L. Palmer, and Miss M. A. C. Jones, who allowed patients under their care to be included in this study. 


\section{References}

AChtiani, A., and wollensak, J. (1966) Ber. dtsch. ophthal. Ges. 1965, 67, 367

ambrosio, A., and D'esposito, M. (I957) Arch. Ottal., 6r, 299

Blodi, f. C., VAn Allen, m. W., and Yarbrough, J. c. (1964) Arch. Ophthal. (Chicago), 72, i 7 I

BREININ, G. M. (I957) Ibid., 57, I 76

BRoWN, B. H., Whitaker, G. E., and moosa, A. (197I) "Proceedings of Conference on Computers

for Analysis and Control in Medical and Biological Research". I.E.E. Conference Publication 79 BUrger, A. (1963) Bull. Soc. Ophtal. Fr., p. 554

Dell'AQuila, A., and molinari, I. (I966) Riv. oto-neurn-oftal., 41, I

hоYт, W. F., and Nachtigaller, H. (1965) Amer. F. Ophthal., 6o, 443

HUBER, A., and ESSLEN, E. (1969) Docum. ophthal., 26, 619

- - - KLOti, R., and martenet, A. c. (1964) v. Graefes Arch. Ophthal., 167, i69

moosı, A., and brown, в. н. (1972) J. Neurol. Neurosurg. Psychiat., 35, 2 i 6

ORLOWsKI, w. J., and KRYCH, J. (1963) Ophthalmologica (Basel), 146, I 78

—_ and wojtowicz, s. (1962) Ibid., 114, 199

ozaWA, T., Gheng-Minoda, K., DAvidowitz, J., and breinin, G. M. (1969) Docum. ophthal., 26, i97

PAPST, w. (1962) Klin. Mbl. Augenheilk., r41, 199

-_ and ESSLEN, E. (1960) Ibid., 137, 306

rose, A. L., and willison, R. G. (1967) J. Neurol. Neurosurg. Psychiat., 30, 403

sato, s. (1960) Jap. J. Ophthal., 4, 57

WOLFF, J. (I9OI) Arch. Ophthal. (N.Y.), 29, 297

ZaUberman, H., and MAgORA, A. (1969) Ophthalmologica (Basel), 157, I Io

- - 